\title{
Analysis and Reporting of Case Studies, Global Healthcare in an Aging Society
}

\author{
Neville Greening \\ UGSM-Monarch Business School Switzerland \\ Email: nipponclippon@gmail.com \\ DOI: $10.31364 / \mathrm{SCIRJ} / \mathrm{v} 7.14 .2019 . P 0419646$ \\ http://dx.doi.org/10.31364/SCIRJ/v7.i4.2019.P0419646
}

Abstract: Global Healthcare in an aging society is a massive challenge for all nations and their respective governments. Naturally, health insurance, wealth fare costs, pension, medical expenses, and nursing care will dramatically increase shortly. The long-term economic, social, and geopolitical implications will be catastrophic for countries who are currently experiencing this phenomenon. The contemplated research will focus on elucidations by Yin (2013 pg. 127), where an analytic case study would be vital in explaining, describing, or exploring phenomenological events in our everyday contexts where they occur. And so, there is a need for repeated sorting as well as reviewing of rich-in-detailed data that is integral to the healthcare context using numerous general strategies (Yin, 2013 pg. 130).

Keywords: Healthcare, aging society, analytic, phenomenological events

Introduction

1.0 Analyzing Case Study Evidence

1.1 Need for an Analytic Case Study

According to elucidations by Yin (2013 pg. 127), an analytic case study can be vital in explaining, describing, or exploring phenomenological events in our everyday contexts where they occur. While analyzing global healthcare in an aging society, making sense and at the same time offering a coherent interpretation of the conventional incongruent data sources, whether quantitative or qualitative, is far from straightforward (Merriam and Tisdell, $2015 \mathrm{pg}$. 73). And so, there is the need for repeated sorting as well as reviewing of rich-in-detailed data that is integral to the healthcare context using the four general strategies (Yin, 2013 pg. 130). Relying on theoretical propositions when analyzing data related to inpatient component cases first, developing a case description before making comparisons across diverse healthcare context, employing both quantitative and qualitative data, where data is subjected to statistical analyses, as well as examining rival explanation through the analysis of competing hypotheses (ACH) 


\subsection{Five Analytic Techniques}

The reports by Yin (2013 pg. 136) claims that none of the analytic techniques that are easy to use, thus the need to compel case study analyses through five primary analytic methods.

\subsubsection{Pattern Matching}

It is widely accepted and one of the most popular techniques in conducting a case study. Pattern-matching logic is essential when distinct sources of data are being integrated and examined (Hébert, 2012 pg. 37). In the case of our research on global healthcare in an aging society, there is the need to strengthen the internal validity in order to explain the connections that exists amongst distinct elements, including, positive health measures such as life satisfaction, performance, the functional status, day-to-day core and instrumental activities, the general healthy aging, the mobility pattern, health care utilization of professionals, as well the physical activity that addresses scale for the elderly (Yin, 2013 pg. 136; and Kalache and Kickbusch, 1997 pg. 112).

\subsubsection{Iterative Nature of Explanation Building}

While analyzing health care issues, and in our case, the researcher will make an initial theoretical statement that can be vital when analyzing using the statistical methods (Hoy et al., 2014 pg. 61). The validity of results are verified via the scrutiny of others, and through this, there is a follow-up of those mechanisms that ensure vitality when data is being collected and analyzed. As Yin (2013 pg. 143) conceptualizes on a comparison of other details of the case against the revision, a researcher should accept that the worldviews are biased, and this can influence the methods used. And so, there is the need to minimize the interaction with research subjects to avoid creating biases in the results.

\subsubsection{Time-Series Analysis}

It is a third analytic technique that involves direct analogous to the time-series analysis that is conducted in experiments and quasiexperiments. On the simple time series on

the aging society, they should give the researcher, or the research team being involved access to the individual groups being assessed (the elderly), the organization, and the processes that constitute our chosen analysis on global healthcare in an aging society. In this case, access is the primary facet of consideration, where the researcher needs to be aware of the case study site(s) and work closely with them (Yin, 2013 pg. 144; and Baxter and Jack, 2008 pg. 49). 


\subsubsection{Logic Models}

It is the fourth technique that is used when doing a case study evaluation. The logic model assists in deliberately stipulating a complex chain of events on the selected cases to be not only attractive but also hospitable to the participants involved in the inquiry, if they are to be informative and adhere to the research evaluation(s). In some cases, the program logic model strategy can also be useful when the researcher wants to make decisions from the key stakeholders using public policy intervention (Yin, 2013 pg. 150). For instance, our selection of case study sites on global healthcare in an aging society might be heavily influenced by variables of social participation, positive health, as well as health equity available in the Census.

\subsubsection{Cross-Case Synthesis}

Cross-case synthesis is the last technique, and it's specifically applicable to the analysis of multiple cases. If the prominent stakeholders involved have performed the individual case studies, cross-case syntheses can be conducted as an independent research study in a competitive bidding process that will enhance development and implementation of the age-friendly initiatives and adoption of a neutral perspective (Yin, 2013 pg. 156). From here, this would be followed by the creation of word tables that display the data from the individual cases in regard to certain uniform framework, either from organizations or the focus groups with thematic content analysis that Yin (2013 pg. 160) described as complementary word tables that can go beyond the single features of a case in exploring how the age-friendly vital components, together with their processes, foster positive health, health equity, and social participation amongst the aging adults. The main significance here is that through case-case synthesis, the researcher will manage to examine the cross-case patterns that rely strongly on argumentative interpretation.

\subsection{Pressing for a High-Quality Analysis}

Furthermore, this will ensure that the report assembled is of the highest quality. For example, there is the need to pay attention to variations in each case, and after that assessing whether the analysis shows all the attended evidence (Yin, 2013 pg. 160; and Moustakas, 1994 pg. 64). It also demands adequate address to all the main rival interpretations from the organization and coding of data to allow fundamental issues, both from the literature and emerging from the healthcare context, easier to retrieve at a later stage. The analysis needs to address the most vital aspect, and that is, capturing certain crucial issues that affect the aged in our society and healthcare giving contexts.

\subsection{Reporting Case Study}

\subsection{Target Case Study Reports}

wWw.scirj.org

(C) 2019, Scientific Research Journal

http://dx.doi.org/10.31364/SCIRJ/v7.i4.2019.P0419XX 
While reporting case studies, the findings can have some implications both for theory testing and development. As mentioned, this goes a long way with the establishment, strengthening or weakening the historical explanations of a case, in turn, allowing certain theoretical generalizations that are beyond the health care in aging context. When reporting findings, it is required of the researcher to provide the reader with enough and satisfying contextual information that will enable easier comprehension of the processes that were followed and how the conclusions were made (Yin, 2013 pg. 169; and Levasseur et al., 2011 pg. 94). The researcher may choose to display the data in tables before amalgamating across other health cases. Thus, care must be taken to make clear that the anonymity of the case study sites and the participants used are appropriately presented, withholding descriptors.

\subsection{Case Study Reports as part of Larger, Mixed Methods Studies}

Embedded within Yin (2013 pg. 173), for a completed case study, there are the trademarks and methods that the researcher ought to follow. It also includes the capability to replicate a multiple cases study design, ability to seek rival explanations on the falsifying hypotheses, the pursuit of generalization, capacity to minimize the subjectivity levels, as well as using multiple methods of both qualitative and quantitative data collection and analysis. When reporting a case study on global healthcare in an aging society, objectivity is the main aim, and Yin (2013 pg. 174) pinpoints the interpretative and descriptive features to use. He makes the case study distinct from other experimental studies. In view of the fact that considering in our case, Yin emphasizes a careful screening that will ensure there is specificity in the relevance of our interesting issue and use of replication logic. It implies that there is the choice of participants and groups to produce anticipated findings that contrast with theoretical and lateral replication.

\section{3 illustrative Structures for Case Study Compositions}

Yin's approach to our case study involves precision, practicality, and process as the core attributes because through sequential structuring, empirical application is motivated, and this enables an axiology of post-positivism where intellectual honesty is being maintained, bias is managed, and limitations are being acknowledged, coupled with meticulous collection of the data and accurate reporting throughout the research (Drummond et.al, 2005 pg. 88). In our study on evaluating global healthcare in aging society, building on linear-analytic structures, comparative structures, chronological structures, theory-building structures, new and existing collaborations, together with generations of evidence is our core components, and the results of this study will over and again help the communities, refine policies, structures, and health care services, and label the society as age-friendly, which will best heighten the positive health outcomes and promote social participation amongst all in the community (Yin, 2013, pg. 177; and Van Dijk, 2013 pg. 127).

wWw.scirj.org

(C) 2019, Scientific Research Journal

http://dx.doi.org/10.31364/SCIRJ/v7.i4.2019.P0419XX 


\subsection{Procedures in Doing a Case Study Report}

In our case, to have a well-developed set of proceedings that will aid in developing our required data and composing an empirical report, there is the need to create an age-friendly context as one of the most innovative procedures when creating any population intervention. Reviewing the draft case study will follow, where the probability of enhancing health equity at a community level will increase (Yin, 2013 pg. 182). Even though the interventions in this study will follow a designation in accordance with asset-based approaches where the collective elderly community is available to heighten their status of health, it will be a process to mobilize researchers, policy-makers, and practitioners to work with the aging population in and outside the healthcare sector in a more reflexive process.

\subsection{What makes it an Exemplary Case Study?}

As a first case study, it will go beyond the methodological procedures. An example in this, in our case, the contemplated research will provide a detailed random strategy that will be significant nationally, through recruiting respondents based on gender, rural or urban areas, and age. As well, it will be a complete case study as it will exceed the boundaries by the participant's inquiry to know the core set of baseline information to employ on health and demographic measures and collecting data from all participants through electronic devices or interviews (Yin, 2013 pg. 186). By considering alternative perspectives and displaying enough evidence, this case study will examine the evidence from different points of view, through ensuring completion based on the participant's context (Porter, 2009 pg. 52)

\section{References}

[1] Baxter, P. and Jack, S., 2008. Qualitative case study methodology: Study design and implementation for novice researchers. The qualitative report, 13(4), pp.544-559.

[2] Drummond, M., Manca, A. and Sculpher, M., 2005. Increasing the generalizability of economic evaluations: recommendations for the design, analysis, and reporting of studies. International journal of technology assessment in health care, 21(2), pp.165-171.

[3] Hébert, R., 2012. Autonomy insurance: An essential innovation in response to the challenges of aging. Canadian Journal on aging = La Revue Canadienne du vieillissement, 31(1), pp.1-11.

[4] Hoy, D., March, L., Brooks, P., Blyth, F., Woolf, A., Bain, C., Williams, G., Smith, E., Vos, T., Barendregt, J. and Murray, C., 2014. The global burden of low back pain: estimates from the Global Burden of Disease 2010 study. Annals of the rheumatic diseases, pp. annrheumdis-2013.

[5] Kalache, A. and Kickbusch, I., 1997. A global strategy for healthy aging. World health, 50(4), pp.4-5. 
[6] Levasseur, M., Gauvin, L., Richard, L., Kestens, Y., Daniel, M., Payette, H. and NuAge Study Group, 2011. Associations between perceived proximity to neighborhood resources, disability, and social participation among community-dwelling older adults: results from the VoisiNuAge study. Archives of physical medicine and rehabilitation, 92(12), pp.1979-1986.

[7] Merriam, S.B. and Tisdell, E.J., 2015. Qualitative research: A guide to design and implementation. John Wiley \& Sons.

[8] Moustakas, C., 1994. Phenomenological research methods. Sage. Porter, M.E., 2009. A strategy for health care reform-toward a value-based system. New England Journal of Medicine, 361(2), pp.109-112.

[9] Porter, M.E., 2009. A strategy for health care reform-toward a value-based system. New England Journal of Medicine, 361(2), pp.109-112.

[10] Van Dijk, T.A., 2013. News analysis: Case studies of international and national news in the press. Routledge.

[11] Yin, R.K., 2013. Case study research: Design and methods. Sage Publications. 